\title{
Annotations
}

\section{Outcome for children subject to non-accidental injury}

Systems for identifying children at risk of child abuse, for intervening when children are abused, and for then monitoring their progress are widely established. The parameters for evaluating the effects of intervention and for determining the outcome for individual children and their families, however, are poorly defined.

\section{Difficulties in evaluating outcome}

In evaluating the effects of intervention and eventual outcome of abused children, reported studies have experienced many practical difficulties. Firstly, the sample size of studied groups is frequently small and follow up of families may be difficult. The information obtained may be incomplete-up to $63 \%$ of injured children have been reported lost to follow up. ${ }^{12}$ This in itself indicates that support for abused children and their families is often inadequate.

Secondly, distinctions need to be drawn between varieties of child abuse. This term encompasses not only non-accidental physical injury but also neglect, emotional deprivation, some subjects with failure to thrive, and sexual abuse. The outcome for any one of these may well not be the same as for the others. What happens to the sexually abused child is particularly dependent on management strategies. Without thorough assessment of family dynamics and sensitive use of available legal and treatment resources, further sexual abuse may occur with failure of normal development of adult sexual behaviour. ${ }^{134}$

Thirdly, the difficulties of using control groups need to be recognised. This has been discussed by Lynch and Roberts ${ }^{5}$ who point out the problems inherent in selecting control families. The ideal family, where perfect child rearing techniques exist, is probably impossible to identify, and such a family would not control for the environmental influences that determine the outcome of child abuse. If the control families have similar parental personality characteristics to abusing families, the children within these families may, at some stage, be abused but without this being identified.

Fourthly, the criteria used to measure outcome merit consideration. Survival alone is insufficient and there is a need to include assessment of children's physical progress, emotional development, educational status, and re-injury rate. Attention must also be paid to what changes have taken place within the family. The interpretation of whether intervention has been successful may also vary between the professionals involved.

It is against this background that research on the outcome for abused children must be evaluated. The published reports include those on children who had multiple skeletal injuries, ${ }^{2}$ who were admitted to a family therapy unit, ${ }^{5}$ who were taken into the care of the local authority, ${ }^{6}$ and those with injuries ranging from mild to severe. ${ }^{1}$

\section{Death and subsequent injury}

Mortality rates, including deaths from subsequent injury, from the long term consequences of abuse or from unrelated causes, have been described in those children who survived their original injury. In recent follow up studies rates of $2.5 \%^{5}$ and $2 \%^{6}$ have been reported. These contrast with earlier studies where the rates were $15 \%{ }^{2}$ and $11 \% .^{7}$ Mortality rates alone cannot, however, be used as the sole criterion of effective intervention. Similarly re-injury rates can be misinterpreted. Once the initial incident has been identified minor injuries will be more readily detected as a result of professional monitoring of the family, the subsequent injuries being less severe than the original one. Rates quoted have been $30 \%{ }^{8}$ in the United States and $20 \%^{5}$ and $10 \%^{6}$ in the United Kingdom.

\section{Physical and neurological development}

Abnormalities of physical and neurological development have been reported after abuse. In many children the abnormalities existed before the original incident. It has been suggested that in as many as $20 \%$ of children with cerebral palsy, abuse was a contributory factor or a response to the handicapping condition. ${ }^{9}$ This has not been shown to be so in Liverpool where $2.5 \%$ of children with cerebral palsy have been abused. ${ }^{10}$ Failure to thrive is recognised as being a feature that is detected both before and after abuse. Although it is often sug- 
gested that provision of a stable environment alone can reverse non-organic failure to thrive, where growth has been studied, growth retardation has been found in up to $31 \%$ of children at follow up. ${ }^{12}{ }^{5}$ IIl health and neurological handicap are also features of abused children. While severe impairment of neurological function is easily identified (occurring in $10 \%$ of children) ${ }^{2} 5$ minor motor dysfunction may not be detected unless specific neurological assessment is performed. When an abused and sibling group have been compared it has been found that the proportion of minor neurological handicap was similar in both. ${ }^{5}$

\section{Emotional and behavioural disturbance}

Emotional problems in abused children may be a result of poor parenting or home environment. Prolonged stays in hospital, uncertainties while case conferences are convened and legal action considered, and lack of communication with parents may prejudice the outcome from an early stage and must also be considered as causative factors. The greater the number of placements a child has after the abuse is detected, the less likely he or she is to have a satisfactory outcome. ${ }^{6}$ The behaviour of emotionally disturbed childiren may also contribute to poor school performance. This may be compounded by the abused child's low self esteem and social isolation. ${ }^{1}$

\section{Intervention strategies}

The methods of intervention may influence the outcome for the abused child. While there is no clear evidence that one form of intervention is more effective than another, once a child has been abused it is important that an early decision be made regarding his future. ${ }^{6}$ Failure to do so results in multiple placements, delayed and inadequate attempts at rehabilitating the child at home with his parents, and the possibility of poor physical, emotional and intellectual development.

Breakdown rates are high for children placed in long term care especially for older children and those who have spent some time previously in care. $^{5}{ }^{11}$ The emotional disturbances experienced by children before abuse is detected may well play a major role in causing breakdown of placements. These then fail because support is not given to the foster parents and the child throughout the placement period.

When children are allowed home, either after the initial presentation or after a period of short term care, those who fare best are those for whom there has been an important change in family circumstances, and intensive therapeutic support both precedes and follows the return to the family. ${ }^{6}$ This support can ideally be provided through a family therapy unit, and in such a unit children who have gone home with their parents after intensive therapy have fared better than those who were removed from their parents. ${ }^{5}$ Unfortunately, such units are not readily available and most abused children and their families depend on support from local agencies in the community. In such circumstances nonprofessionals, including the extended family, may have an important role in providing this support and should be included when therapeutic regimens are being planned. $^{8}$

\section{Conclusion}

Even given our inadequate evaluation criteria, especially for emotional development and family functioning, it is clear that children who have been abused may well do poorly. This failure of present intervention regimens indicates not only a need for their improvement but also that prevention of child abuse must be the ultimate aim.

\section{References}

1 Martin HP, Beezley P, Conway ES, Kempe CH. The development of abused children. Adv Pediatr 1974;21:25-73.

2 Elmer E, Gregg GS. Developmental characteristics of abused children. Pediatrics 1967:40:596-602.

${ }^{3} \mathrm{Kempe} \mathrm{CH}$. Sexual abuse, another hidden pacdiatric problem: the 1977 C Anderson Aldrich lecture. Pediatrics 1978;62:382-9.

${ }^{4}$ Beczley Mrazek P. Sexual abuse of children. J Child Psychol Psychiatry 1980;21:91-5.

5 Lynch MA, Roberts J. Consequences of child abuse. London: Academic Press, 1982.

${ }^{6}$ Hensey OJ, Williams JK, Rosenbloom L. Intervention in child abuse: experience in Liverpool. Dev Med Child Neurol 1983;25: 606-11.

${ }^{7}$ Kempe CH, Silverman FN, Stecle BF, Droegmueller W, Silver HK. The battered child syndrome. JAMA 1962;181: $17-24$.

${ }^{x}$ Cohn AH. The pediatrician's role in the treatment of child abuse: implications from a national evaluation study. Pediatrics 1980;65:358-61

9 Diamond LJ, Jaudes PK. Child abuse in a cerebral-palsied population. Dev Med Child Neurol 1983;25:169-74.

10 Henscy O, Ilett SJ, Rosenbloom L. Child abuse and cerebral palsy. Lancet 1983;ii:400.

"Prosser H. Perspectives on residential care. Windsor, Berks: NFER, 1976

L Rosenbloom AND

O J HeNSEY Child Development Centre, Alder Hey Children's Hospital, Liverpool L12 $2 A P$ 